\title{
Specialized cephalic skin glands of Suncus murinus viridescens
}

\author{
Eugene MARY and M. BALAKRISHNAN
}

Mary E. and Balakrishnan M. 1991. Specialized cephalic skin glands of Suncus murinus viridescens. Acta theriol. 36: 187 - 192.

Skin histology of the shrew, Suncus murinus viridescens (Blyth) have revealed the presence of meibomian and nasal glands heretofore unreported in shrews. Both are modified sebaceous glands. Apocrine sweat glands are associated with nasal sebaceous acini. Meibomian glands of this species are associated with hair follicles and are not sexually dimorphic.

Department of Zoology, University of Kerala, Karivattom 695 581, Trivandrum, Kerala, India

Key words: cephalic skin glands, Suncus murinus viridescens, India

\section{Introduction}

Major sources of behaviourally relevant odours in mammals are secretions of specialized integumentary glands (Mykytowycz 1970, Müller-Schwarze 1983, Balakrishnan and Alexander 1985), saliva (Schultze-Westrum 1965, Poduschka 1977, Gray et al. 1984), urine (Kleiman 1966, Peters and Mech 1975, Nyby et al. 1985) and faeces (Ewer 1967, Mykytowycz 1970). The significant role of specialized skin glands in scent marking and in the social behaviour of mammals have been stressed recently (Eisenberg and Kleiman 1972, Johnson 1973, Adams 1980, Gosling 1982, Müller-Schwarze 1983).

Classical information on specialized integumentary glands of several species of mammals revealed by Schaffer (1940) was followed by a series of investigations by Quay $(1954,1955$, 1962, 1965, 1968) and others (Mykytowycz 1970, Quay and Müller-Schwarze 1970, Montagna 1971). Although shrews have also been the subject of such investigations (Pearson 1946, Dryden and Conaway 1967, Hutterer 1985), most of the information is restricted to Europaean or North American species and little is available about the larger Indian species (Balakrishnan and Alexander $1977 \mathrm{a}, \mathrm{b})$. Further, soricided meibomian and nasal glands have not been reported on shrews. This paper concerns the histomorphology of specialized cephalic integumentary glands in the Indian musk shrew, Suncus murinus viridescens (Blyth).

\section{Material and methods}

Shrews were live-trapped near University Campus, Karivattom and maintained in individual wire mesh cages on minced beef, fish, cockroaches and tap water ad libitum for at least a week before they were killed with ether. Skin samples from the upper and lower eyelids and the preorbital snout were fixed in Bouin's fluid, $10 \%$ formalin and in $70 \%$ alcohol and processed by routine histological procedure. Paraffin sections were cut at $6 \mu \mathrm{m}$ and 
stained in Erlich's haematoxylin and eosin, and studied under a binocular microscope. Measurements were made using an ocular micrometer. Sections of skin samples from adjacent body regions served as control samples. Measurements of 10 largest glandular acini were averaged to arrive at the size. Data from 10 males, 10 females and 10 immature shrews of both sexes were used and were analysed for significance using Student's $t$-test.

\section{Results}

\section{Meibomian glands (Acinar glands)}

Specialized integumentary glands identified as meibomian glands were seen on the edges of the upper and lower eyelids of both sexes (Fig. 1). Large, paired, sebaceous acini arranged in a single row were associated with hair follicles (Fig. 2). Holocrine sebaceous acini were perpendicularly oriented in a plane towards the free edges of the eyelids. Hence the bilobate and saccular nature of the glands were readily visible (Fig. 3). These glandular lobes were highly enlarged compared with sebaceous acini in control samples. The glands were more numerous and the lobes were smaller at the junction of the eyelids than on other areas (Fig. 4).

The epidermal layer of the glanduar tubules consisted of stratified epithelium about $20 \mu \mathrm{m}$ thick. Mean length and width of the sebaceous acini were $125 \mu \mathrm{m}$ and $39 \mu \mathrm{m}$ in males and $116 \mu \mathrm{m}$ and $36 \mu \mathrm{m}$, respectively, in females. The dermis containing sebaceous acini were encapsulated in a thin layer of connective tissue. Cross sections of each meibomian lobe contained $18-25$ cells. The glanduar ducts were with cuboidal epithelium and they opened directly on the surface of the skin (Figs. 2 and 3). Flat eosinophilic cells with ovoid nuclei occupied the periphery of the glandular acini. Centroacinar cells had round nuclei and were polyhedral. This gland was not sexually dimorphic $(p>0.05)$. Adults had greater masses of gland with larger nuclei than did immature shrews $(p<0.05)$.

\section{Nasal glands}

Nasal glands occupied an oval band of $10 \mathrm{~mm}$ by $15 \mathrm{~mm}$ above the oral angle on both sides (Fig. 1). It contained sebaceous and sudoriferous acini in both sexes of Suncus murinus. Apocrine sudoriferous glands were located more deeply than were sebaceous acini (Fig. 5).

The stratified epithelium of the dermis had glandular cells of about $25 \mu \mathrm{m}$ thick. The mean length and width of the sebaceous acini were $146 \mu \mathrm{m}$ and $36 \mu \mathrm{m}$ in males and $123 \mu \mathrm{m}$ and

Fig. 1. Head of a male Suncus murinus showing specialized glandular zones: A (eyelids), B (nasal glandular area).

Fig. 2. Sebaceous acini of meibomian glands with hair follicle in a female shrew. $\times 100$.

Fig. 3. Vertical section of eyelid showing the modified sebaceous acini with common ducts. $\times 100$.

Fig. 4. The junction of eyelids of the shrew is with large accumulation of the meibomian glands. $\times 100$.

Fig. 5. Sebaceous acini and associated apocrine sudoriferous glands of the nasal glandular area of a female shrew. $\times 100$.

Fig. 6. An enlarged view of the sebaceous acini of nasal glands of a male shrew. $\times 400$.

Fig. 7. Apocrine glandular tubules seen in the nasal glandular area of a male shrew:

asg (apocrine sudoriferous glands), hf (hair follicle), mg (meibomian glands), sa (sebaceous acini). $\times 400$. 


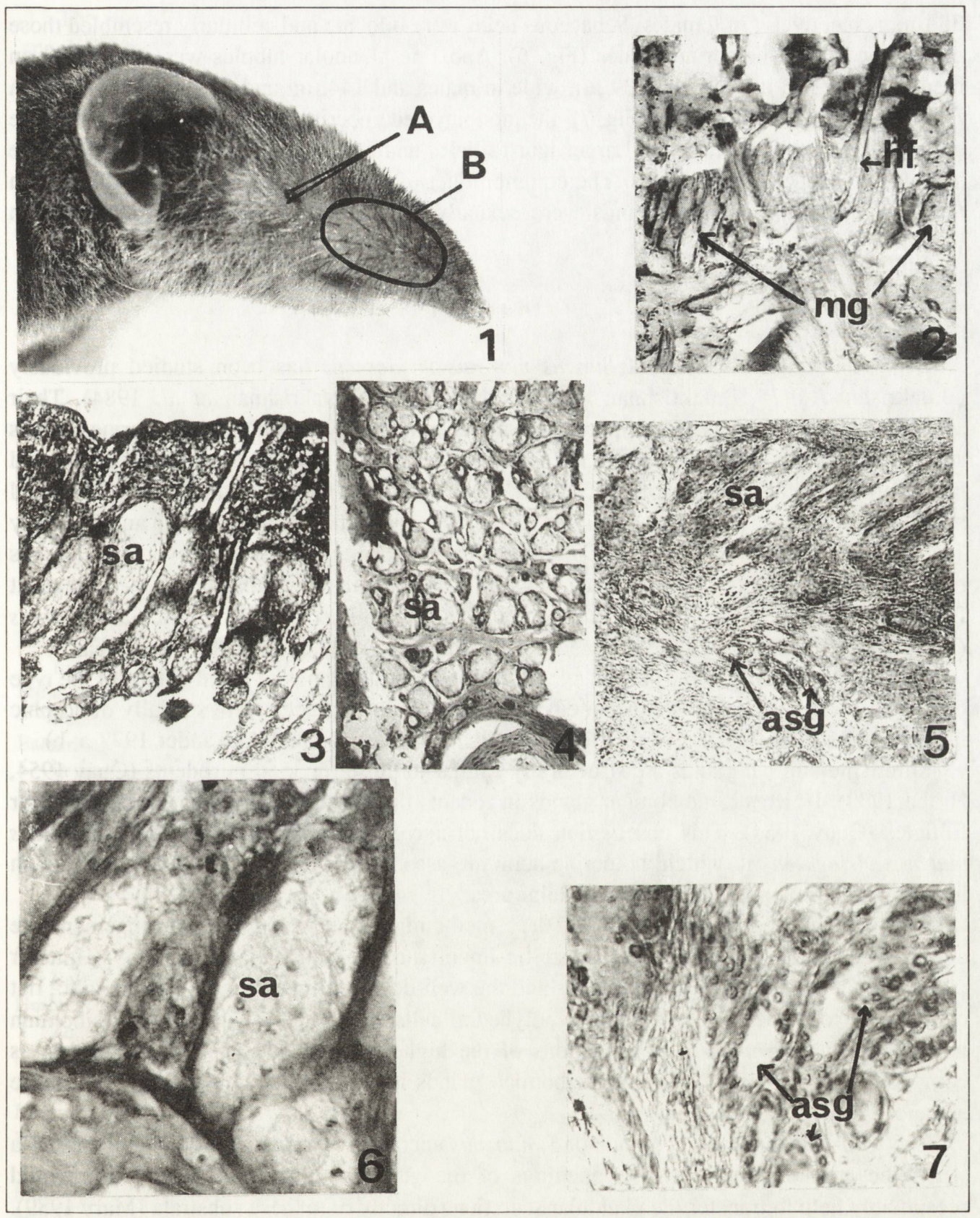


$38 \mu \mathrm{m}$, respectively, in females. Sebaceous acini were bilobate and cellularly resembled those of the specialized holocrine tissues (Fig. 6). Apocrine glandular tubules were located in an area of about $146 \mu \mathrm{m}$ long and $39 \mu \mathrm{m}$ wide in males and $144 \mu \mathrm{m}$ and $36 \mu \mathrm{m}$ respectively in females. In magnified sections (Fig. 7), the monolayered apocrine sudoriferous nature of these glandular tubules was revealed. Larger hair follicles and sudoriferous glandular tubules were seen in the deeper dermal zones. The common duct of each pair of acini opened directly on the skin surface. The nasal glands were sexually monomorphic and poorly developed in juveniles.

\section{Discussion}

Scent marking behaviour of Suncus murinus viridescens has been studied previously (Balakrishnan 1975, Balakrishnan and Alexander 1976, Balakrishnan et al. 1984). Their specialized integumentary glands play a major role in olfactory communication during various social interactions (Balakrishnan and Alexander 1980). These observations necessitated histomorphological studies of specialized integumentary glands of possible behavioural revelance. Some specialized glands of this species were described earlier (Dryden and Conaway 1967, Balakrishnan and Alexander 1977 a, b). During social interactions, shrews of both sexes rely considerably on scents of cephalic region (Balakrishnan and Alexander 1980). Frequent facial grooming, nasal sniffing and foot drumming after rubbing the eye area in Suncus murinus (Mary 1989) have revealed the probability of glanduar sites on eyelids and nasal areas.

Modified sebaceous glands of the eyelids are meibomian glands or tarsal glands of the type described by Quay (1954). Neither meibomian nor the nasal glands were sexually dimorphic in S. murinus as in the case of their other glands (Balakrishnan and Alexander $1977 \mathrm{a}, \mathrm{b}$ ).

Shrew meibomian glands are structurally similar to those reported in rodents (Quay 1954, Hrabe 1979). However, meibomian glands in rodents do not develop in association with hair follicles (Quay 1954). This observation does not agree with the present findings in Suncus murinus viridescens in which, holocrine acini are associated with hair follicles, even though hair growth seems reduced in the glandular area.

The number of glandular acini of the meibomian glands and their arrangement are considered to have generic or even specific importance in mammalian taxonomy (Hutterer 1985). The biacinal nature of the glands and the well-developed, peripheral, eosinophilic, flat cells with ovoid nuclei and the central polyhedral cells with round nuclei of the meibomian glands in Suncus murinus are reflections of the higher pylogenetic age of the species, as compared to the lower number of meibomian glands in the evolutionary younger and more advanced rodent species (Quay 1954).

The well-developed nasal glands of $S$. murinus encounter various environmental substrata when the animals explore. The openings of the glandular ducts on the exterior would presumably help to transfer the glandular secretions directly onto these substrata (Mary 1989).

It is known that mammals are equipped with more integumentary glandular sites on the head region so as to be more efficient in transferring diverse communication signals during social interactions (Walther 1979). It is also known that the more diverse the glandular sites on the species, the more efficient would be the transfer of signals (Mykytowycz 1970). 
The present investigation has confirmed our earlier view that the cephalic region may have specialized cutaneous glands. This was based on observations of intense use of the cephalic region for olfactory cues by scent marking and by sniffing the region intensively during various interspecific social interactions (Balakrishnan and Alexander 1980, Mary 1989). Other specialized integumentary glands of the head region such as the post-auricular apocrine glands (Dryden and Conaway 1967) and the oral lip and angle glands of this species were alredy reported (Balakrishnan and Alexander 1977 a).

Acknowledgements: The University Grants Commission, New Delhi, The University of Kerala and the Management of Mar Ivanios College, Trivandrum kindly permitted EM to undertake this investigtion. We also thank K. M. Alexander for encouragement and facilities.

\section{References}

Adams M. G. 1980. Odour producing organs of mammals. Symp. Zool. Soc. London 45: 57 - 86.

Balakrishnan M. 1975. Studies on mammalian behaviour: Aspects of ethology of the indian musk shrew, Suncus murinus viridescens (Blyth). Ph. D. thesis, University of Kerala: $1-326$.

Balakrishnan M. and Alexander K. M. 1976. Hormonal control of marking behaviour of the male musk shrew, Suncus murinus viridescens (Blyth). Horm. Behav. 7: 431 - 439.

Balakrishnan M. and Alexander K. M. 1977 a. Specialized mucocutaneous junction glands of the Indian musk shrew. Acta theriol. 22: $231-240$.

Balakrishnan M. and Alexander K. M. 1977 b. Histology and histochemistry of the flank glands of the Indian musk shrew. Acta theriol. 22: $241-249$.

Balakrishnan M. and Alexander K. M. 1980. A study on scent marking and its olfactory inhibition in the Indian musk shrew, Suncus murinus viridescens (Blyth). Bonn. zool. Beitr. 31: 2 - 13.

Balakrishnan M. and Alexander K. M. 1985. Sources of body odour and olfactory communication in some Indian mammals. Indian Rev. Life Sci. 5: 277 - 313.

Balakrishnan M., Shelly T. A. and Alexander K. M. 1984. Role of progesterone on the control of scent marking in Suncus murinus viridescens (Blyth). Physiol. Behav. 33: 415 - 419.

Dryden G. L. and Conaway C. H. 1967. The origin and hormonal control of scent production in Suncus murinus. J. Mammal. 48: 420 - 428.

Eisenberg J. F. and Kleiman D. G. 1972. Olfactory communication in mammals. Ann. Rev. Ecol. Syst. 3: 1 - 32.

Ewer R. F. 1967. The behaviour of the African giant rat (Cricetomys gambianus Waterhouse). Z. Tierpsychol. 24: $6-79$.

Gosling L. M. 1982. A reassessment of the function of scent marking in territories. Z. Tierpsychol. 60: 89 - 118 .

Gray B., Fisher R. B. and Meunier G. F. 1984. Preferences of salivary odour cues by female hamster. Horm. Behav. 18: 451 - 456.

Hrabe V. 1979. Tarsal glands in Microtus nivalis mirhanreini from the western, high and Belanske. Folia Zool. 28: $231-235$.

Hutterer R. 1985. Anatomical adaptations of shrews. Mamm. Rev. 15: 43-55.

Johnson R. P. 1973. Scent marking in mammals. Anim. Behav. 21: 521 - 535.

Kleiman D. 1966. Scent marking in the Canidae. Symp. Zool. Soc. London 18: 167 - 177.

Mary E. 1989. Studies on some specialized integumentary glands and behaviour of the Indian musk shrew, Suncus murinus viridescens (Blyth). Ph. D. thesis, University of Kerala: $1-196$.

Montagna W. 1971. Cutaneous comparative biology. Arch. Derm. 104: 577 - 591.

Müller-Schwarze D. 1983. Scent glands in mammals and their functions [In: Advances in the study of mammalian behaviour. J. F. Eisenberg and D. G. Kleiman, eds]. Plenum Press, New York: 150 - 197.

Mykytowycz R. 1970. Role of skin glands in mammalian communication. [In: Advances in chemoreception, 1. communication by chemical signals. J. W. Johnston Jr., D. G. Moulton and A. Turk, eds]. AppletonCentury-Crofts, New York: $327-360$. 
Nyby J., Edwinkay N., Jay B., Zeno D. and Michael K. 1985. Male mouse (Mus musculus) attraction to air borne urinary odours of conspecific and to food odours. J. Comp. Psychol. 99: 479 - 490.

Pearson O. P. 1946. Scent glands of the short tailed shrew. Anat. Rec. 94: 615 - 630 .

Peters R. and Mech L. D. 1975. Scent marking in wolves. Amer. Scient. 63: 628 - 637.

Poduschka W. 1977. Insectivore communication. [In: How animals communicate. T. A. Sebeok, ed.]. Indiana University Press, Bloomington and London: 600 - 633 .

Quay W. B. 1954. The dorsal holocrine skin gland of the kangaroo rat (Dipodomys). Anat. Rec. 119: 161 - 175.

Quay W. B. 1955. Histology and histochemistry of skin gland areas in the caribou, Rangifer. J. Mammal. 36: $187-201$.

Quay W. B. 1962. Apocrine sweat glands in the angulus oris of microtine rodents. J. Mammal. 43: 303 - 310 .

Quay W. B. 1965. Integumentary modifications of North American desert rodents. [ In: Biology of skin and hair growth. A. G. Lyne and B. F. Short, eds]. Angus and Robertson, Sydney: $59-74$.

Quay W. B. 1968. The specialized postero-lateral sebaceous glandular regions in microtine rodents. J. Mammal. 49: $427-445$.

Quay W. B. and Müller-Schwarze D. 1970. Functional histology of integumentary glandular regions in black tailed deer (Odocoleus hemionus columbianus). J. Mammal. 51: $675-694$.

Schaffer J. 1940. [In: Die Hautdrüsenorgane der Säugetiere]. Urban and Schwarzenberg, Berlin and Wien: $1-464$.

Schultze-Westrum T. 1965. Innerartliche Verstandigung durch Dufte beim Gleitbeutler, Petaurus breviceps papuanus Thomas (Marsupialia, Phalangeridae). Z. vergl. Physiol. 50: 151-220.

Walther F. 1979. Das Verhalten der Hornträger (Bovidae). Handb. Zool. 8: 1 - 84.

Received 15 February 1991, accepted 8 July 1991. 